\title{
Attitude towards the discipline of physics- chemistry and school achievement: revisiting factor structure to assess gender differences in Portuguese high-school students
}

\section{Paulo Vilia \& Adelinda A. Candeias}

To cite this article: Paulo Vilia \& Adelinda A. Candeias (2020) Attitude towards the discipline of physics-chemistry and school achievement: revisiting factor structure to assess gender differences in Portuguese high-school students, International Journal of Science Education, 42:1, 133-150, DOI: $10.1080 / 09500693.2019 .1706012$

To link to this article: https://doi.org/10.1080/09500693.2019.1706012

\section{Published online: 23 Dec 2019.}

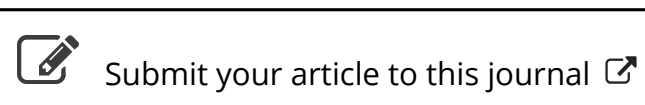

\section{Џ Article views: 72}

Q View related articles ¿

$$
\text { View Crossmark data } \longleftarrow
$$




\title{
Attitude towards the discipline of physics-chemistry and school achievement: revisiting factor structure to assess gender differences in Portuguese high-school students
}

\author{
Paulo Vilia (D) and Adelinda A. Candeias \\ School of Social Sciences and Centre for Educational Research and Psychology, University of Évora, Évora, \\ Portugal
}

\begin{abstract}
The importance of attitudes and other variables of the affective domain in education is acknowledged for a long time. In this study, we used an attitude questionnaire to survey 498 Portuguese 9th-grade students to determine the predictive ability of the attitudes towards the discipline of Physics-chemistry on school achievement. Possible gender differences were also investigated after establishing the measurement invariance of the factor structure. The survey instrument presented some issues regarding factor structure. After a new factor analysis using more robust statistical methods, a four-factor structure of attitudes towards Physics-chemistry - Competence to discipline, Pleasure in learning, Anxiety, and Utility - was established and used in this study. The means of the Competence and the Pleasure in learning factors were significantly higher in the boy's group while the factors Anxiety and Utility were not significantly different between genders. Competence was the most important achievement predictor, with significant positive effects, while the factors Anxiety and, surprisingly, Pleasure in learning presented significant negative impacts on the grades. The possible reasons and consequences for these results are discussed, and some suggestions are made about the importance of considering the relevance of affective variables on teaching and learning highschool Physical sciences.
\end{abstract}

\section{ARTICLE HISTORY}

Received 3 March 2019

Accepted 13 December 2019

\section{KEYWORDS}

Attitude towards the discipline of physicschemistry; school achievement; gender differences; high-school

\section{Introduction}

The importance of science and technology in modern societies is continuously growing, with an increasing number of decisions both at global and at individual levels being based or requiring some level of scientific knowledge. Moreover, the massive amounts of information and the growing rate of change in society oblige everyone to 'think like a scientist', weighing evidence to come to conclusions and understanding that today's 'truth' may change over time as progress continues (Organisation for Economic Co-operation and Development [OECD], 2016). In this context, the school science disciplines play a very significant role providing the students both with the basis of scientific

CONTACT Paulo Vilia pnrcvv@gmail.com $\Theta$ School of Social Sciences and Centre for Educational Research and Psychology, University of Évora, Évora, Portugal 
knowledge and also with the understanding of the correct procedures and practices of science and its limitations (OECD, 2016; Tytler, 2014).

The importance of attitudes and other variables of the affective and motivational domain in education is acknowledged for a long time (e.g. Eccles et al., 1983 in Eccles \& Wigfield, 2002). However, school and society in general, tend to assign cognitive abilities the dominant role when defining school curricula or when explaining and evaluating student's success or failure (Tytler \& Osborne, 2012).

The research about students' attitudes toward science, demonstrated that attitudes play a vital role in their present and future engagement with science, and are relevant for the process of deciding whether or not to choose science as a future field of study or considering it as a future career (Mujtaba, Sheldrake, Reiss, \& Simon, 2018; Osborne, Simon, \& Collins, 2003; Reid, 2015; Tytler \& Osborne, 2012). In the same direction, previous work from Eccles and Wigfield (2002) shows that student's achievement and achievement-related choices are determined by their expectation of success and subjective task values.

The number of previous studies regarding the attitudes towards school science in Portugal is scanty and with mixed results. Neto (1995) in his PhD thesis examined the degree of satisfaction of 10th-grade Portuguese students with the discipline of Physics during an experimental trial using problem-solving strategies and found a significant decrease in the control group exposed to traditional teaching and no improvements in the experimental groups. On the contrary, Fernandes (2007) working with a sample of 450 9th-grade students refers that they consider the discipline of Physics-chemistry interesting, accessible and related to the daily life, but without influence in the choice of their future career. This author also reports the existence of gender differences favouring the girls both in the attitudes and in achievement.

In Portugal, Physics-chemistry is one of two compulsory science disciplines (the other is Natural Sciences) students must attend in the last three years of the common branch education (7th to 9th-grades). In the 9th year, to which the data used in this study refers, chemistry concepts taught include the basis of atomic structure, chemical bonding or the Periodic Table, and physics covers themes like electricity, movement or forces (Fiolhais et al., 2013).

In this study, we analysed the contribution of student's attitudes towards the discipline of Physics-chemistry, as predictors of achievement in a sample of Portuguese 9th -grade students. We chose to focus on this discipline because the students regard it as the most challenging and less relevant for everyday life (Osborne et al., 2003; Wang, Chow, Degol, \& Eccles, 2017). We also examined the differences between boys and girls regarding this school subject since it is known that there are significant gender differences in attitudes towards school science in particular in physics and chemistry with girls generally showing less positive attitudes (Wan \& Lee, 2017).

\section{Literature review}

Research on student attitudes toward science has struggled with the problem of the precise definition of attitude (Tytler, 2014). In a review covering research from 2000 to 2012 on interest, motivation, and attitude towards science and technology at the K-12 level, Potvin and Hasni (2014) found that 71 out of 121 articles referring attitude as a central concept, did not specify a definition. Eagly and Chaiken (1998) proposed a simple and broad 
definition that is widely accepted: 'an attitude is a psychological tendency that is expressed by evaluating a particular entity with some degree of favour or disfavour'.

The questionnaire used in this study was initially developed in the framework of Eagly and Chaiken's (1998) aforementioned definition of attitude and also the tripartite model of attitude structure (Rosenberg and Hovland, 1960 in Eagly \& Chaiken, 1998). This model is the most classical and accepted one and, considers responses elicited by the attitude object to be formed by three components: cognition - the knowledge or beliefs about the attitude object, affect - the feelings about the attitude object, and behaviour- the tendency towards action about the attitude object. Each of these three components may be more or less positive or negative, which reinforce the evaluative nature of attitudes proposed by Eagly and Chaiken definition (Eagly \& Chaiken, 1998; Reid, 2015).

The careful identification of the construct being studied is a critical stage when researching the students' attitudes towards school science (Tytler, 2014) and, two issues must be clarified. The first is that attitudes towards a specific school science discipline and, attitudes towards science in general, are two different constructs with the former being more likely to be significant to student's learning and to influence their decisions to continue to study sciences in post-compulsory levels (Tytler \& Osborne, 2012). The second is that very often attitude towards school science is measured as a unitary construct, while in many countries, Portugal included, science is taught in three or four different subjects. Each subject represents a different attitude target and measure them in a unitary way may yield biased results (Can \& Boz, 2012; Cheung, 2009). This research refers specifically to the attitudes towards a specific school discipline (Physics-chemistry) and not to attitudes towards science in general.

The relevance of attitudes and other related factors of the affective domain on students' achievement on school-science subjects such as physics, chemistry or biology, has been studied for a long time (e.g. Gardner, 1974; Schibeci \& Riley, 1986). Although not entirely consensual among the research community, most studies report that attitudes or some of its related subconstructs are significant predictors of school science achievement.

Akbas and Kan (2007) and Vahedi and Yari (2014) studying respectively chemistry and physics report adverse effects of anxiety in high-school students' achievement. In the same study, these last authors also mention a positive relationship between positive attitudes towards physics and physics achievement. Other authors such as Ali and Awan (2013) also that found a positive association between attitudes towards science and the results in physics and chemistry of 10th-grade Indian students. Xu, Villafane, and Lewis (2013) similarly refer that attitudes towards chemistry are a significant predictor of first-year college students' achievement.

Other more general models about the role of motivation, affect, and attitudes in academic achievement and student's decisions are also important to understand students' performance. A relevant framework proposed by Eccles et al. (1983 in Eccles \& Wigfield, 2002) - expectancy-value theory - considers that achievement-related choices are determined by expectancies for success, and subjective task values. Expectancies refer to how confident a child is in his or her ability to succeed in an upcoming task whereas task values refer to how important, useful, or enjoyable the individual perceives the task (Eccles \& Wigfield, 2002). These constructs, although not directly linked with the attitude concept, may help to understand the relation between the attitudes and its different sub-constructs, and students' achievement. 
Gender differences in attitude towards school science are also a question frequently studied for quite a long time (Wan \& Lee, 2017). See, for example, the meta-analysis conducted by Steinkamp and Maehr (1984 in Cheung, 2009) referring data from 1965 to 1981, or another by Weinburgh (1995) using research published between 1970 and 1991 . Despite this vast amount of data, research presented mixed results. Steinkamp and Maehr (1984 in Cheung, 2009) report that girls' attitudes towards chemistry were more positive than boys' and that the opposite occurs about physics; on the contrary, Weinburgh's (1995) meta-analysis concluded that the girl's attitudes were lower than the boys' in $81 \%$ of the studies reviewed.

This situation continues to occur in more recent works. Salta and Tzougraki (2004), studying Greek high-schoolers' attitudes towards school chemistry did not find gender differences except in the 'difficulty' sub-scale where girls were more negative than boys. Cheung (2009) and Can and Boz (2012) studying, respectively Hong Kong and Turkish secondary students' attitudes on the same school subject found that gender differences were grade related. Dhindsa and Chung (2003) found that gender differences in Bruneian students depended on the school type (single-sex or co-educational) and the attitude subconstruct considered. Seba, Ndunguru, and Mkoma (2013) working with high-school Tanzanian students report significant differences favouring boys' attitudes towards school physics and chemistry. Atasoy, Ergin, and Şen (2014) found similar results on two subconstructs of attitude towards physics (Expectations and Hesitations about physics course) after an experimental intervention using peer instruction method with 9th-grade Turkish students. Kousa, Kavonius, and Aksela (2018) also report that Finnish high-school girls show more negative attitudes than boys.

\section{Method}

\section{Participants}

The data for this study were collected as a part of a research project - 'Academic Performance and Development: a longitudinal study on the effects of school transitions in Portuguese student' (PTDC/CPE-CED/104884/2008), aimed at assessing the effects of numerous of variables on the achievement of Portuguese basic education students.

This study used data collected on the 9th-grade students attending the discipline of Physics-chemistry from twelve Portuguese schools, representing the three administrative, educational regions from the mainland: North ( 3 schools), Centre ( 3 schools) and South (4 schools) and the Azores ( 2 schools). The sample includes 498 students ( 284 girls $-57,0 \%$ and 214 boys $-43,0 \%)$, ages $14-16($ mean $=14.35 \pm 0.60)$ representing approximately $0.5 \%$ of all 9 th grade Portuguese students.

\section{Procedure}

This study was approved by the Scientific Committee of the University of Évora. Before data collection, informed consent from the parents, permission from the school's directors and authorisation from National Committee for the Protection of Data and Committee for Monitoring Surveys in Schools from the Ministry of Education were obtained. Students' 
participation was voluntary and anonymous, and all data was kept confidential and anonymous.

The surveys were completed in a single 15-minute session during classroom time, in the presence of the class teacher and a member of the research team. After statistical, treatment this data was used as a measure of the student's attitudes and utilised to determine the predictive ability of attitudes in the school grades on each of the three school terms.

\section{Instruments}

The Attitudes Towards Physics-Chemistry Questionnaire (ATPCQ) was developed within the framework of the previously mentioned project. The instrument comprised 26 items, each answered in a 4-category Likert-type response format, ranging from strongly agree (4 points) to strongly disagree (1 point). The negatively worded items were reversed scored.

The initial psychometric analysis (Neto et al., 2011) suggested the existence of five factors: pleasure, easiness and dislike in studying physics-chemistry, utility of physicschemistry in everyday life, and a fifth factor with item loadings smaller than .60. In a second study, the authors proposed a three-dimensional structure with a motivational, an affective and a behavioural factor but concluded that further analyses were needed namely because the motivational factor seemed to include items referring utility and easiness in studying physics-chemistry (Neto, Candeias, Rebelo, Varelas, \& Diniz, 2013). Considering the existing doubts about the factor structure of the questionnaire, we decided to use our data to reanalyse it before studying the predictive ability of attitudes on school achievement.

\section{Data analysis}

The data collected were analysed using the statistical software packages IBM- SPSS21 and Mplus7.11 (Muthén \& Muthén, 2012).

To assess the factor structure of the questionnaire we used a traditional approach performing an Exploratory Factor Analysis (EFA) followed by Confirmatory Factor Analysis (CFA) to establish and verify the number factors and the pattern of item-factor relationships (Brown, 2015). The sample was randomly split in half using SPSS random split procedure $\left(\mathrm{n}_{1}=245, \mathrm{n}_{2}=253\right)$, and each subsample was used for one of the analyses $\left(\mathrm{n}_{1}-\mathrm{EFA}\right.$ and $\mathrm{n}_{2}-$ CFA).

Given that the previous results published for this questionnaire pointed to a five-factor (Neto et al., 2011) or a three-factor structure (Neto et al., 2013), we decided to compare EFA models with two to five factors to determine the optimal number of factors. According to Asparouhov and Muthén (2009), the selection of the optimal number of factors can be made using model fit information, although $\chi^{2}$ difference tests have been shown to present a tendency for extracting too many factors.

Both EFA and CFA were performed using Mplus 7.11 with robust weighted least squares estimator (WLSMV), currently considered the most accurate estimator for EFA and CFA modelling with categorical data (Brown, 2015).

In EFA, we used Geomin rotation, which was developed as a compromise between seeking simple pattern loading structure and attempting that variables load primarily on a single factor, provided that an interpretable solution exists (Sass \& Schmitt, 2010). 
The selection of the rotation criterion is critical when conducting EFA as it gives vital information about the factor structure complexity and the inter-factor correlations which are essential, especially in test construction and validation (Sass \& Schmitt, 2010).

The global adjustment quality of the various models tested was assessed using the indices: $\chi^{2}$, Root Mean Square Error of Approximation (RMSEA), Comparative fit index (CFI) and Tucker-Lewis index (TLI) and their respective reference values (Brown, 2015; Marôco, 2014). The local adjustment quality was evaluated by the factor loading and the individual reliability of the items. When necessary, the model adjustment was improved using the modification indices suggested by Mplus and on the basis of theoretical knowledge. The Composite Reliability (CR) and the Average Variance Extracted (AVE) for each factor were determined as described by Fornell and Larcker (1981).

To investigate possible differences between the attitudes of boys and girls towards the discipline of Physics-chemistry as defined in the objectives of the present study, we tested the measurement invariance of ATPCQ across gender. Drawing valid statistical conclusions from comparisons between mean-level differences in multiple groups require that measurement invariance is established, once the nature and magnitude of relationships between items and the latent constructs may differ across groups, preventing their scores from being interpreted in the same way (Bowen \& Masa, 2015; Sass, 2011).

Testing measurement invariance usually follows a hierarchal sequence comparing a series of nested models, each with more equality constraints across groups than the previous (Bowen \& Masa, 2015). The invariance test begins with the assessment of Configural invariance (equivalence of the model structures), followed by the evaluation of Metric invariance (equivalence of factor loadings) and finishes with the test of Scalar invariance (equivalence of indicator thresholds). If factor loadings and item thresholds are invariant over groups, then changes in the latent factor means can be compared (Marsh et al., 2010). The methodology followed to test the invariance is explained in more detail in Appendix A.

After determining the factor structure of attitudes towards the discipline of Physicschemistry as measured by the ATPCQ, the predictive ability of the different attitudinal dimensions on the student's school achievement was investigated by regressing the school grades on each school term on each of the attitudinal factors. This analysis was conducted both for the entire sample and for boys and girls separately, after establishing the measurement invariance between boys and girls.

\section{Results}

The model fit information of the various EFA models tested (two to five factors), presented in Table 1 shows that the approximate fit indices (RMSEA, CFI, and TLI), improved with the increasing number of factors, reaching acceptable values for solutions including four and five factors. The fact that the $\chi^{2}$ test of exact fit rejected the null hypothesis of exact fit to the data in all the models tested is not surprising considering that this test is very sensitive to sample size, routinely rejecting models even when the differences to the sample data are negligible (Brown, 2015).

The analysis of the factor structure is an important step when deciding the number of factors to be considered in a measurement instrument (Brown, 2015). The factor structure of the four and five factors EFA solutions is similar; however, the fifth factor is an 'empty 
Table 1. Goodness-of-fit statistics for the EFA models tested to determine the number of factors.

\begin{tabular}{lccccccccc}
\hline & $X^{2}(\mathrm{df})$ & CFI & TLI & $\begin{array}{c}\text { RMSEA } \\
(90 \% \mathrm{Cl})\end{array}$ & $\begin{array}{c}\text { Prob. } \\
\text { RMSEA } \leq .05\end{array}$ & $\Delta X^{2}(\mathrm{df})$ & $\Delta$ CFI & $\Delta$ TLI & $\Delta$ RMSEA \\
\hline M2 2 factors & $1315.40^{* *}(274)$ & .923 & .909 & $.125(.118-.131)$ & .000 & - & - & - & - \\
M3 3 factors & $913.45^{* *}(250)$ & .951 & .937 & $.104(.097-.111)$ & .000 & $308.84(24)$ & .028 & .028 & -.021 \\
M4 4 factors & $432.19^{* *}(227)$ & .985 & .978 & $.061(.052-.069)$ & .023 & $336.53(23)$ & .034 & .041 & -.043 \\
M5 5 factors & $395.59^{* *}(205)$ & .986 & .978 & $.062(.052-.071)$ & .020 & $58.73(22)$ & .001 & .000 & .001 \\
\hline
\end{tabular}

Note: RMSEA $(90 \% \mathrm{Cl})=90 \%$ confidence interval for the RMSEA point estimate; ${ }^{* *} p \leq .001$.

factor' on which no items have the main loading. The four factors solution is easy to interpret concerning item content, with a coherent item distribution and factor loadings on the principal factor always higher than .45, except for two items. Considering the results of the multiple criteria and taking into consideration the substantive content of the various factors generated, we elected the four-factor solution.

In accordance with standard practice an item to be retained should: (a) have a factor load of at least .40 in the principal factor; (b) show factor loadings inferior to .35 on the other factors and (c) the difference between the loading in the primary factor and the remaining should be over .15 (Marôco, 2014). Items 5, 6, 9, 11 failed to meet at least one of these criteria and were discarded. The final scale, used for further analysis, has 22 items.

Standardised factor loadings indicate that all items loaded strongly $(.75<\lambda<.91)$ in their intended factor, and $R^{2}$ estimates ranged from .56 to .90 (average $=.86 \pm .04$ ) indicating that large amounts of each item variance are explained by the respective latent construct. The composite reliability (CR) values, all exceeding .9, suggested adequate reliability and, the average variance extracted (AVE) estimates, ranging from .75 to .78, support the convergent validity of the model (Hair, Black, Babin, \& Anderson, 2014). All the AVE estimates for each factor were greater than the squared inter-construct correlations associated with that factor and all the correlations between factors were lower than the cutoff value of .85 (Brown, 2015) indicating that there are no problems of discriminant validity (Hair et al., 2014).

We named the resulting four factors: Pleasure in learning (6 items - Example item: Attending Physics-Chemistry classes is pleasant), Anxiety (6 items - Example item: The discipline of Physics-Chemistry annoys me), Competence (6 items - Example item: I can achieve good results in Physics-Chemistry without difficulty) and Utility (4 items Example item: I think that Physics-Chemistry are useful in day-to-day life).

In order to be able to use all the individuals in our sample, we tested the invariance of the four-factor model in both subsamples, the one utilised for EFA and the one used for CFA, using the invariance test procedure proposed by Mplus. The results showed that the model structure (configural invariance), the factor loadings (metric invariance), and the indicator thresholds (scalar invariance) were statistically equivalent in both subsamples allowing us to use the total sample in all subsequent analysis.

The four-factor model adjusted to the entire sample presented marginally acceptable values of some model fit indices. However, the incorporation of some covariances between error terms associated to items within the same factor (Items 3-18, 8-14, 1921 , and 26-27) improved the model adjustment to acceptable values: CFI $=.985$, TLI $=.982$ and $\mathrm{RMSEA}=.066, \mathrm{P}(\mathrm{RMSEA} \leq .005)=.001$. 
Figure 1 presents the fully standardised factor loadings and the residual variances of each item. As with the model obtained using only the CFA subsample, all items presented strong factor loadings in their intended factor $(.75<\lambda<.92)$ and a high proportion of their variance was explained by their respective underlying factor as seen by the small residual variances.

The CR values were all superior to .9 indicating good factor reliability and, the AVE estimates were always superior to $.68(.68<\mathrm{AVE}<.79)$ demonstrating the convergent validity of the model (Hair et al., 2014). The AVE estimates for each factor were larger than

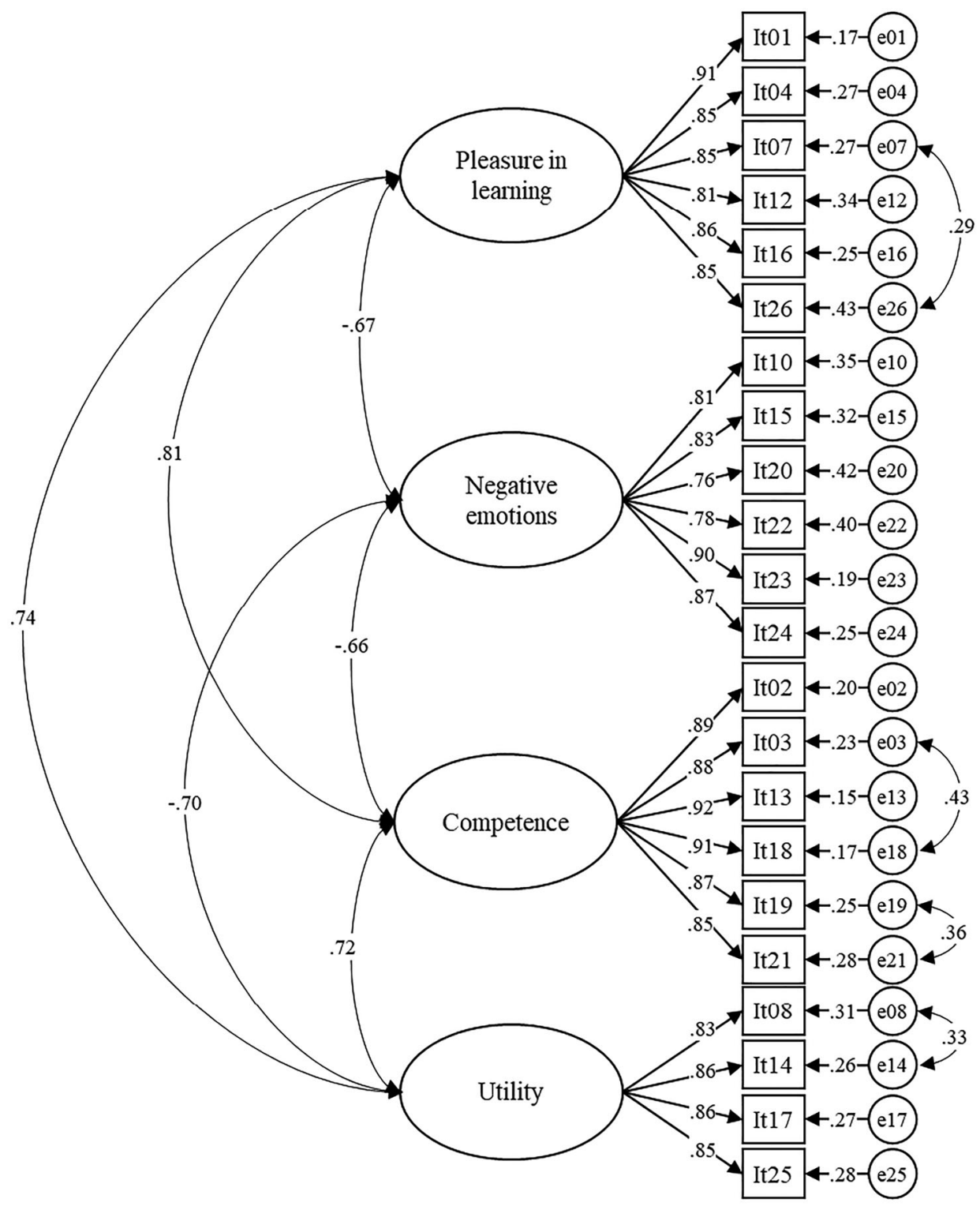

Figure 1. Final four-factor model of attitudes towards the physics-chemistry discipline adjusted to a sample of 4989 th grade Portuguese students. 
the squared inter-construct correlations associated with that factor and all the correlations between factors were lower than the cutoff value of .85 (Brown, 2015) indicating that there are no problems of discriminant validity (Hair et al., 2014) (Table 2).

In order to investigate possible differences between boys' and girls' attitudes, we assessed the measurement invariance of the final four-factor solution in our sample between those two groups. The results showed that the model structure (configural invariance), the factor loadings (metric invariance), were statistically equivalent in both groups. The analysis of the model concerning threshold equality indicated that one or more thresholds were noninvariant. However, the source of non-invariance was only the third threshold of item 22 (Factor - Anxiety). With only one noninvariant parameter found among all tested, we decided for the acceptance of scalar invariance as proposed by several authors (e.g. Dimitrov, 2010; Millsap \& Olivera-Aguilar, 2012) (For further details refer to Appendix B).

Having established the model invariance between boys and girls, we proceed to compare the means of the four factors between those two groups. The factor means are not directly observed since they are the means of latent constructs and, so it is not possible to compare their values because the unit of measurement is not the same on each group. However, when conducting multigroup CFA, the factor means of one group are fixed to zero while in the other group they are freely estimated, establishing the first as a reference against which the other is compared (Brown, 2015). The multigroup model presented an acceptable model fit: $\mathrm{CFI}=.983$, TLI $=.983$ and $\mathrm{RMSEA}=.063, \mathrm{P}(\mathrm{RMSEA} \leq .005)=.001$. Given that the girls' group was defined as reference group by default, we shall focus our analysis on the estimates for the boys' group. The means of factors Anxiety $(p=.322)$ and Utility $(p=.91)$ in the boys were not significantly different from the girl's group whereas the means of the factors Competence (STDYX standardised $\alpha=.362, p \leq .001$ ) and Pleasure in learning (STDYX standardised $\alpha=.269, p \leq .005$ ) were significantly different.

The model fit of the causal model including the effect of the four factors on the Physicschemistry grades on each of the three school terms revealed a good adjustment (CFI $=.982$, TL $\mathrm{I}=.981$ and RMSEA $=.058, \mathrm{P}(\mathrm{RMSEA} \leq .005)=.010)$. The fully standardised weights of the causal trajectories are presented in Table 3. The results show that the factor Competence presents the strongest predictive effect on the school grades, with $\beta$ values always higher than .595. The factors Pleasure in learning $(-.37<\beta<-.55)$ and Anxiety $(-.25<\beta<-.27)$ also presented statistically significant, but negative effects on the grades of all three school terms. The factor Utility never presented statistically significant predictive values. In all factors, values raised from the first to the second terms and decreased in the third term, although the amount of variation was always relatively small.

Table 2. Standardised construct correlation matrix for the final four-factor CFA model.

\begin{tabular}{lcccc}
\hline & Anxiety & Competence & Pleasure & Utility \\
\hline Anxiety & 1 & .437 & .454 & .439 \\
Competence & -.661 & 1 & .663 & .513 \\
Pleasure & -.674 & .814 & 1 & .540 \\
Utility & -.702 & .716 & .735 & 1 \\
\hline
\end{tabular}

Note: Values below the diagonal are correlation estimates among constructs, diagonal elements are construct variances, and values above the diagonal are squared correlations. 
Table 3. Fully standardised effects of the four attitude factors on the physics-chemistry grades.

\begin{tabular}{|c|c|c|c|c|c|c|}
\hline & \multicolumn{2}{|c|}{1 st term grade } & \multicolumn{2}{|c|}{ 2nd term grade } & \multicolumn{2}{|c|}{3 rd term grade } \\
\hline & \multicolumn{2}{|c|}{ Total } & \multicolumn{2}{|c|}{ Total } & \multicolumn{2}{|c|}{ Total } \\
\hline & Girls & Boys & Girls & Boys & Girls & Boys \\
\hline Anxiety & $\begin{array}{r}-.246^{* *}(.066) \\
-.191(123)\end{array}$ & $-238 * *(078)$ & $\begin{array}{r}-.274^{* *}(.067) \\
-.275^{*}(113)\end{array}$ & $-239^{*}(083)$ & $\begin{array}{r}-.269^{* *}(.067) \\
-267^{*}(120)\end{array}$ & $-.261^{*}(.08$ \\
\hline Competence & $\begin{array}{l}.754^{* *}(.076) \\
838^{* *}(096)\end{array}$ & . 250 & $.761^{* *}(.079)$ & $668 * *(121)$ & $.595^{* *}(.082)$ & \\
\hline Pleasure in & $\begin{array}{r}.030 \\
-.497^{* *}(.084)\end{array}$ & $.620^{* *}(.126)$ & $\begin{array}{r}.808^{* * *}(.106) \\
-.550^{* *}(.084)\end{array}$ & $.668^{* *}(.121)$ & $\begin{array}{r}.659^{* *}(.109) \\
-.367^{* *}(.096)\end{array}$ & $.381^{*}(.136$ \\
\hline learning & $-.527^{* *}(.114)$ & $-.397^{* *}(.111)$ & $-.596^{* *}(.115)$ & $-.447^{* *}(.111)$ & $-.436^{* *}(.129)$ & $-.208(.124)$ \\
\hline Utility & $\begin{array}{r}-.092(.080) \\
.068(.112)\end{array}$ & $.176(.132)$ & $\begin{array}{l}.072(.078) \\
.023(.109)\end{array}$ & $.162(.129)$ & $\begin{array}{l}.088(.077) \\
.024(.108)\end{array}$ & . $257(.137)$ \\
\hline
\end{tabular}

Notes: Values in bold - entire sample, Values in brackets - standard error; ${ }^{*} p \leq .005,{ }^{* *} p \leq .001$.

The results obtained considering the girls and boys separately followed a similar trend with Competence always presenting the stronger (positive) predictive effect, followed by Pleasure in learning and Anxiety with negative effects. The effects of Utility were again always non-significant. Comparing the results between boys and girls, the effects of both Competence and Pleasure in learning were consistently stronger in the girls' group, whereas for Anxiety, the results were similar for both groups.

\section{Discussion and conclusions}

The middle-school years are fundamental in developing personal interest and positive attitudes towards science, which in turn are a strong predictor of achievement and career interest (Wang et al., 2017). In Portugal, the 9th-grade is the last year of the common branch in education after which students must choose what study area they pursue, which renders this study especially relevant in particular if we consider the scarcity of research and instruments developed for Portugal.

The first set of results from this study has to do with the analysis of the factor structure of the questionnaire used for attitudinal data collection. The four-factor model suggested by the EFA and posteriorly confirmed through CFA revealed an acceptable adjustment quality and was easy to interpret regarding item content, with an intelligible item distribution on each of the four factors.

Our four factors are similar in content to factors found in other studies on attitudes towards school science, validating, in this way, the results of our research (e.g. Potvin \& Hasni, 2014). The factors Pleasure in learning and Anxiety, respectively expressing the pleasant and the disagreeable feelings and sensations evoked by studying or attending Physic-chemistry classes can be compared to factors or subconstructs like enjoyment (Can \& Boz, 2012; Dhindsa \& Chung, 2003; Wan \& Lee, 2017), emotional satisfaction (Xu \& Lewis, 2011), liking for chemistry classes (Cheung, 2009; Demircioğlu, Aslan, \& Yadigaroğlu, 2014), liking for science (Mattern \& Schau, 2002), anxiety (Bauer, 2008; Dhindsa \& Chung, 2003), interest in physics (Veloo, Nor, \& Khalid, 2015), enjoyment and anxiety to science (Wan \& Lee, 2017), anxiety (Akbas \& Kan, 2007).

The Competence factor, made up of items associated with the ability to have good results or being skilful when solving problems or performing Physics-Chemistry activities can be related to factors like the difficulty of chemistry course (Salta \& Tzougraki, 2004) difficulty of understanding physics (Veloo et al., 2015), cognitive competence in science 
(Mattern \& Schau, 2002), self-efficacy in chemistry (Kan \& Akbaş, 2006), intellectual accessibility in chemistry (Ross, Nuñez, \& Lai, 2018), ability self-concept in physics and chemistry (Wang et al., 2017), self-concept in science (Mujtaba et al., 2018; Wan \& Lee, 2017).

Utility factor refers to the perceived utility of Physics-Chemistry for daily life and can thus be compared to factors or subconstructs such as value of science (Mattern \& Schau, 2002), usefulness for future career (Salta \& Tzougraki, 2004), importance for student life (chemistry - Can \& Boz, 2012; Dhindsa \& Chung, 2003; Salta \& Tzougraki, 2004; physics Veloo et al., 2015), interest and utility (Ross et al., 2018), career plans for chemistry (Demircioğlu et al., 2014).

The result indicating the measurement invariance of the factor structure between boys and girls in our sample allowed us to compare their attitudes towards the subject of Physics-chemistry. The means of the Competence and the Pleasure in learning factors were significantly higher in the boy's group while the factors Anxiety and Utility did not show significant differences. These results convey the notion that boys see themselves as more competent in performing activities related to the discipline Physics-chemistry and take more pleasure in doing them when compared to girls On the other hand, boys and girls are similar in their anxiety towards the discipline and their sense of its usefulness for daily life.

Although, as mentioned earlier, the overall literature analysis reveals mixed results, our results are consistent several studies reporting that girls hold more negative attitudes than boys (e.g. Kousa et al., 2018; Seba et al., 2013). Kousa et al. (2018) refer that girls in their study felt that chemistry is tedious and complicated and that they will not need the chemistry skills in the future, on the contrary boys thought that they were more successful in chemistry and found both chemistry and its tasks easier than girls. These results are coherent with the differences favouring boys' attitudes found in the factors competence and pleasure in learning found in our study.

Seba et al. (2013), and Salta and Tzougraki (2004) suggest that the more positive attitudes shown by boys can be related to the existence of social, educational and cultural factors affecting negatively female students' attitudes. A related point of view is made by Kessels, Rau, and Hannover (2006) that measured implicit attitude towards physics in a study about the image of physics of 11th-grade German students. Having found that girls associated physics with difficulty and with masculinity more than boys, the authors suggest that girls might not express their interest in physics because it would compromise their newly acquired identity as a women-to-be and endanger their femininity and popularity with boys.

The persistence of socio-cultural factors impairing girls' attitudes may also occur in Portugal and could help explain the differences, favouring the boys found in this study, since physics and, to lesser degree chemistry are still seen as boy's subjects. This opinion is supported by studies conducted with chemistry high-school students from Australia (Cousins \& Mills, 2015) or in a report about gender balance in physics enrolment in UK high-schools (Institute of Physics, 2017) where gender stereotyping, including by girls themselves, is present even though attainment levels are similar.

The results concerning the contribution of the different factors as predictors of the achievement revealed that Competence was the most important predictor both when considering the full sample and when considering boys and girls separately. This result was 
expected since the content of this factor is similar to several other found to be relevant in other studies and is closely related to the ability self-concept construct present in Eccles' expectancy-value theory (Eccles \& Wigfield, 2002). According to this theory, confidence in onés abilities to succeed is an important factor explaining the choice of activities and engagement in those activities. In the case of students, if they feel confident in their capacity to succeed in a particular school subject (in our case Physics-chemistry), they are more likely to engage deeper with that discipline and its activities which in turn will lead to increased academic achievement (Eccles \& Wigfield, 2002).

The Anxiety factor showed a significant negative effect on Physics-chemistry grades on all three school terms for both the entire sample and for boys and girls separately. This was an expected result since anxiety is known to have a negative influence on school achievement (Sahin, Caliskan, \& Dilek, 2015; Zusho, Pintrich, \& Coppola, 2003). Akbas and Kan (2007) report that anxiety is a significant predictor of chemistry achievement in highschool Turkish students explaining up to $15 \%$ achievement variance. Vahedi and Yari (2014) also found a significant correlation between anxiety and physics' grades in highschool Iranian students.

The negative result for the predictive ability of the Pleasure in learning factor, was somewhat surprising in that a negative relationship was not expected since most studies report a positive association between attitudes or its components and achievement (Ali \& Awan, 2013; Vahedi \& Yari, 2014; Xu et al., 2013). The explanation for this result, that is in the line of the study by Neto (1995) where the degree of satisfaction of 10th-grade Portuguese students decreased significantly in the group exposed to traditional teaching, may reside in the nature of teaching in Portuguese schools where the teaching objectives are mainly oriented to the evaluations - performance goals, and not to the development of competences and task mastery - mastery goals. It is generally accepted that performance goal orientated-teaching undervalues the learning process and the pleasure it produces and hinders students' academic performance (Zusho et al., 2003).

The non-significant results found for the utility factor, although contrary to previous results reported by Fernandes (2007) for Portuguese students, were not surprising once, it is commonly accepted that most students find the themes taught uninteresting and without any use for them for their everyday life.

Overall our results are consistent with previous research that establishes the importance of affective variables, including attitudes, in high-school science teaching and learning as can be seen by the predictive ability of some attitudinal factors. The relevance of the Competence factor, also coincident with other reports, is particularly significant since it has obvious implications for physics and chemistry teaching namely the use of strategies to improve student's confidence in themselves and convey the notion that physical sciences are indeed learnable and useful.

It was also possible to establish the factor structure of the attitudes measured by the Attitude towards Physics-chemistry, which is a significant result given the scarcity of school attitudinal measuring instruments in Portuguese.

The results of this study are based on a single administration of the questionnaire and should, therefore, be verified by repeating it with different samples. Further research should also use qualitative methods to allow a more in-depth understanding of students' attitudes and its implications in the learning process. 
To conclude, results point out for the importance of taking into account the affective component when teaching science, and in particular physics and chemistry, choosing methods more 'student-friendly' (e.g. laboratory and practical work or inquiry-based methods) or contents more relatable to day-to-day life. This will help enhance students' interest and pleasure in learning and reduce anxiety. It is also important to adopt strategies to minimise the stereotypic image of Physics and Chemistry as being masculine sciences promoting gender equity in science learning.

\section{Disclosure statement}

No potential conflict of interest was reported by the authors.

\section{Funding}

This work was supported by Fundação para a Ciência e a Tecnologia [grant number PTDC/CPECED/104884/2008,SFRH/BD/90575/2012].

\section{Notes on contributors}

Paulo Vilia is a $\mathrm{PhD}$ student in Educational Sciences at University of Évora. His $\mathrm{PhD}$ research project focus on the affective and cognitive variables affecting the achievement of Portuguese middle school students in Science subjects (Physics and Chemistry, Natural Sciences). He taught Natural Sciences and Natural Sciences Didactics as an assistant professor at Polytechnic Institute of Beja, Portugal between 2001 and 2012.

Adelinda Candeias has an MD \& PhD in Psychology (Psychology of Education). She is also Associate Professor in Developmental and Educational Psychology at the University of Évora, teaching in the Bachelor in Psychology, in the Master Programs in Educational Psychology and Special Education, and in the PhD Programs in Psychology and Education. She is a member of the Centre for Educational Research and Psychology from the University of Évora and has coordinated several national and international research projects in educational psychology. She has co-edited several books among them With a different glance: Dynamic Assessment and Functioning of Children Oriented at Development \& Inclusive Learning (2011) and, has several publications in journals and book chapters.

\section{ORCID}

Paulo Vilia (i) http://orcid.org/0000-0003-4066-8673

Adelinda A. Candeias (D) http://orcid.org/0000-0002-9489-8880

\section{References}

Akbas, A., \& Kan, A. (2007). Affective factors that influence chemistry achievement (motivation and anxiety) and the power of these factors to predict chemistry achievement-II. Journal of Turkish Science Education, 4(1), 10-19.

Ali, M. S., \& Awan, A. S. (2013). Attitude towards science and its relationship with students' achievement in science. Interdisciplinary Journal of Contemporary Research in Business, 4(10), 707-718.

Asparouhov, T., \& Muthén, B. (2009). Exploratory structural equation modeling. Structural Equation Modeling: A Multidisciplinary Journal, 16(3), 397-438. 
Atasoy, Ş, Ergin, S., \& Şen, A. İ. (2014). The effects of peer instruction method on attitudes of 9thgrade students towards physics course. Eurasian Journal of Physics and Chemistry Education, 6 (1), 88-98.

Bauer, C. F. (2008). Attitude toward chemistry: A semantic differential instrument for assessing curriculum impacts. Journal of Chemical Education, 85(10), 1440-1445.

Bowen, N. K., \& Masa, R. D. (2015). Conducting measurement invariance tests with ordinal data: A guide for social work researchers. Journal of the Society for Social Work and Research, 6(2), 229-249.

Brown, T. A. (2015). Confirmatory factor analysis for applied research (2nd ed.). New York, NY: Guilford Publications.

Can, H. B., \& Boz, Y. (2012). A cross-age study on high school students attitudes toward chemistry. International Journal on New Trends in Education \& Their Implications (IJONTE), 3(3), 82-89.

Chen, F. F. (2007). Sensitivity of goodness of fit indexes to lack of measurement invariance. Structural Equation Modeling: A Multidisciplinary Journal, 14(3), 464-504.

Cheung, D. (2009). Students' attitudes toward chemistry lessons: The interaction effect between grade level and gender. Research in Science Education, 39(1), 75-91.

Cousins, A., \& Mills, M. (2015). Gender and high school chemistry: Student perceptions on achievement in a selective setting. Cambridge Journal of Education, 45(2), 187-204.

Demircioğlu, G., Aslan, A., \& Yadigaroğlu, M. (2014). Exploratory factor analysis study for the scale of high school students' attitudes towards chemistry. International Journal on New Trends in Education \& Their Implications (IJONTE), 5(1), 38-45.

Dhindsa, H. S., \& Chung, G. (2003). Attitudes and achievement of Bruneian science students. International Journal of Science Education, 25(8), 907-922.

Dimitrov, D. M. (2010). Testing for factorial invariance in the context of construct validation. Measurement and Evaluation in Counseling and Development, 43(2), 121-149.

Eagly, A., \& Chaiken, S. (1998). Attitude structure and function. In D. T. Gilbert, S. T. Fiske, \& G. G. Lindzey (Eds.), The handbook of social psychology (pp. 269-322). New York: McGraw-Hill.

Eccles, J. S., \& Wigfield, A. (2002). Motivational beliefs, values, and goals. Annual Review of Psychology, 53(1), 109-132.

Fernandes, C. A. (2007). A matemática na disciplina de ciências físico-quimicas: um estudo sobre as atitudes de alunos do $9^{\circ}$ ano de escolaridade [Mathematics in the discipline of physical-chemical sciences: A study on the attitudes of students in the 9th-year of schooling] (Master's thesis). Retrieved from Repositorium UMinho http://hdl.handle.net/1822/8140

Fiolhais, C., Ferreira, A. J., Constantino, B., Portela, C., Braguez, F., Ventura, G., \& Rodrigues, S. (2013). Metas curriculares do $3^{\circ}$ ciclo do ensino básico [Curricular goals of the 3rd-cycle of basic education]. Lisboa: Ministério da Educação e da Ciência, Governo de Portugal.

Fornell, C., \& Larcker, D. F. (1981). Evaluating structural equation models with unobservable variables and measurement error. Journal of Marketing Research, 18, 39-50.

Gardner, P. L. (1974). Sex differences in achievement, attitudes, and personality of science students: A review. Research in Science Education, 4(1), 231-258.

Hair, J., Black, W., Babin, B., \& Anderson, R. (2014). Multivariate data analysis (7th ed.). Harlow: Pearson Education Limited.

Institute of Physics. (2017). Improving gender balance - reflections on the impact of interventions in schools. Retrieved from Institute of Physics website https://www.iop.org/publications/iop/2017/ page_69173.html

Kan, A., \& Akbaş, A. (2006). Affective factors that influence chemistry achievement (attitude and self efficacy) and the power of these factors to predict chemistry achievement-I. Journal of Turkish Science Education, 3(1), 76-85.

Kessels, U., Rau, M., \& Hannover, B. (2006). What goes well with physics? Measuring and altering the image of science. British Journal of Educational Psychology, 76(4), 761-780.

Kousa, P., Kavonius, R., \& Aksela, M. (2018). Low-achieving students' attitudes towards learning chemistry and chemistry teaching methods. Chemistry Education Research and Practice, 19(2), 431-441. 
Marôco, J. (2014). Análise de Equações Estruturais: Fundamentos teóricos, software \& Aplicações [Structural equation analysis: Theoretical fundamentals, software \& applications] (2nd ed.). Pêro Pinheiro: ReportNumber.

Marsh, H. W., Lüdtke, O., Muthén, B., Asparouhov, T., Morin, A. J. S., Trautwein, U., \& Nagengast, B. (2010). A new look at the big five factor structure through exploratory structural equation modeling. Psychological Assessment, 22(3), 471-491.

Mattern, N., \& Schau, C. (2002). Gender differences in science attitude-achievement relationships over time among white middle-school students. Journal of Research in Science Teaching, 39(4), 324-340.

Millsap, R. E., \& Olivera-Aguilar, M. (2012). Investigating measurement invariance using confirmatory factor analysis. In R. H. Hoyle (Ed.), Handbook of structural equation modeling (pp. 380392). New York, NY: The Guilford Press.

Mujtaba, T., Sheldrake, R., Reiss, M. J., \& Simon, S. (2018). Students' science attitudes, beliefs, and context: Associations with science and chemistry aspirations. International Journal of Science Education, 40(6), 644-667.

Muthén, L., \& Muthén, B. (2012). Mplus version 7 [computer software]. Los Angeles, CA: Muthen \& Muthen.

Neto, A. (1995). Contributos para uma Nova Didáctica da Resolução de Problemas: um estudo de orientação metacognitiva em aulas de Física do Ensino Secundário [Contributions to a new didactics of problem solving: A metacognitive orientation study in secondary physics classes] (Doctoral dissertation). Retrieved from REpositório Universidade de Évora http://hdl.handle. net/10174/10992

Neto, A., Candeias, A., Pomar, C., Costa, P., Oliveira, M., Silva, S., ... Rebelo, N. (2011, September). Questionários de Atitudes Face à Língua Portuguesa (QAFLP), Matemática (QAFM), Ciências da Natureza (QAFCdN), Ciências Naturais (QAFCN) e Ciências Físico-Químicas (QAFCFQ) em Alunos Portugueses Do Ensino Básico: Estudo Psicométrico [Attitudinal questionnaires towards Portuguese Language (QAFLP), Mathematics (QAFM), Sciences of Nature (QAFCdN), Natural Sciences (QAFCN) and Physical and Chemical Sciences (QAFCFQ) in Portuguese students of basic education: Psychometric study]. Poster session presented at XI Congreso Internacional Galego-Portugués de Psicopedagoxía. Universidade da Coruña, Coruña, España.

Neto, A., Candeias, A. A., Rebelo, N., Varelas, D., \& Diniz, A. M. (2013, September). Validade estrutural do questionário de atitudes face às ciências físico-químicas: Estudo com alunos do $9^{\circ}$ ano ensino básico português [Structural validity of the questionnaire of attitudes towards the physical-chemical sciences: Study with 9th-grade Portuguese elementary school students]. Poster session presented at XII Congresso Internacional Galego-Português de Psicopedagogia, Universidade Minho, Braga, Portugal.

Organisation for Economic Co-operation and Development. (2016). PISA 2015 results (volume I): Excellence and equity in education. Paris: OECD Publishing.

Osborne, J., Simon, S., \& Collins, S. (2003). Attitudes towards science: A review of the literature and its implications. International Journal of Science Education, 25(9), 1049-1079.

Potvin, P., \& Hasni, A. (2014). Interest, motivation and attitude towards science and technology at K-12 levels: A systematic review of 12 years of educational research. Studies in Science Education, 50(1), 85-129.

Reid, N. (2015). Attitude research in science education. In M. S. Khine (Ed.), Attitude measurements in science education: Classic and contemporary approaches (pp. 3-46). Charlotte: Information Age Publishing.

Ross, J., Nuñez, L., \& Lai, C. C. (2018). Partial least squares structural equation modeling of chemistry attitude in introductory college chemistry. Chemistry Education Research and Practice, 19 (4), 1270-1286.

Sahin, M., Caliskan, S., \& Dilek, U. (2015). Development and validation of the physics anxiety rating scale. International Journal of Environmental and Science Education, 10(2), 183-200.

Salta, K., \& Tzougraki, C. (2004). Attitudes toward chemistry among $11^{\text {th }}$-grade students in high schools in Greece. Science Education, 88(4), 535-547. 
Sass, D. A. (2011). Testing measurement invariance and comparing latent factor means within a confirmatory factor analysis framework. Journal of Psychoeducational Assessment, 29(4), 347-363.

Sass, D. A., \& Schmitt, T. A. (2010). A comparative investigation of rotation criteria within exploratory factor analysis. Multivariate Behavioral Research, 45(1), 73-103.

Schibeci, R. A., \& Riley, J. P. (1986). Influence of students' background and perceptions on science attitudes and achievement. Journal of Research in Science Teaching, 23(3), 177-187.

Seba, J. M., Ndunguru, P. A., \& Mkoma, S. L. (2013). Secondary school students' attitudes towards chemistry and physics subjects in Tarime-Mara, Tanzania. Tanzania Journal of Natural and Applied Sciences, 4(2), 642-647.

Tytler, R. (2014). Attitudes, identity, and aspirations toward science. In N. G. Lederman \& S. K. Abell (Eds.), Handbook of research in science education (Vol. 2, pp. 82-103). New York: Routledge.

Tytler, R., \& Osborne, J. (2012). Student attitudes and aspirations towards science. In B. J. Fraser, K. Tobin, \& C. J. McRobbie (Eds.), Second international handbook of science education (pp. 597625). Dordrecht: Springer.

Vahedi, S., \& Yari, M. (2014). Role of cognitive and emotional factors on educational achievement among high school students in physics. European Online Journal of Natural and Social Sciences, 3 (3), 572-579.

Veloo, A., Nor, R., \& Khalid, R. (2015). Attitude towards physics and additional mathematics achievement towards physics achievement. International Education Studies, 8(3), 35-43.

Wan, Z. H., \& Lee, J. C. K. (2017). Hong Kong secondary school students' attitudes towards science: A study of structural models and gender differences. International Journal of Science Education, 39(5), 507-527.

Wang, M.-T., Chow, A., Degol, J. L., \& Eccles, J. S. (2017). Does everyone's motivational beliefs about physical science decline in secondary school?: Heterogeneity of adolescents' achievement motivation trajectories in physics and chemistry. Journal of Youth and Adolescence, 46(8), 18211838.

Weinburgh, M. (1995). Gender differences in student attitudes toward science: A meta-analysis of the literature from 1970 to 1991. Journal of Research in Science Teaching, 32(4), 387-398.

$\mathrm{Xu}, \mathrm{X}$., \& Lewis, J. E. (2011). Refinement of a chemistry attitude measure for college students. Journal of Chemical Education, 88(5), 561-568.

Xu, X., Villafane, S. M., \& Lewis, J. E. (2013). College students' attitudes toward chemistry, conceptual knowledge and achievement: Structural equation model analysis. Chemistry Education Research and Practice, 14(2), 188-200.

Zusho, A., Pintrich, P. R., \& Coppola, B. (2003). Skill and will: The role of motivation and cognition in the learning of college chemistry. International Journal of Science Education, 25(9), 10811094. 


\section{Appendices}

\section{Appendix A. Measurement invariance testing}

Testing measurement invariance usually follows a hierarchal sequence comparing a series of nested models each with more equality constraints across groups than the previous (Bowen \& Masa, 2015). The invariance test begins with the assessment of Configural invariance involving the simultaneous estimation of a model, identical for each group, with all parameters freely estimated, such that only similarity of the overall pattern of parameters is evaluated (Bowen \& Masa, 2015; Sass, 2011). This model provides a test of the ability of the model to fit the data in both groups and a baseline for comparing other models with parameter constraints (Marsh et al., 2010). Metric invariance is then tested constraining unstandardised factor loadings to be equal across groups, indicating that the latent constructs are defined in the same way in the various groups (Sass, 2011). Finally, Scalar invariance, showing that individuals with the same score on a latent factor answer the items similarly, is evaluated constraining all thresholds of all items across groups to equality. If factor loadings and item thresholds are invariant over groups, then changes in the latent factor means can be compared (Marsh et al., 2010).

The comparison of each model needed to determine the various levels of invariance is typically made using the significance in $\chi^{2}$ change for two nested models (Bowen $\&$ Masa, 2015). However, some researchers have proposed the use of some other fit indices on account of $\chi^{2}$ over sensitivity in large samples: $\triangle$ RMSEA; $\Delta$ CFI, $\Delta$ TLI (Chen, 2007; Marôco, 2014). Chen (2007) suggested that $\Delta \mathrm{CFI}$ is the most adequate, with $\Delta \mathrm{CFI}<-.01$ indicating model non-invariance. In this study, we base the decision on $\Delta \chi^{2}$, but we also present other indices variations.

\section{Appendix B. Measurement invariance testing detailed results}

To allow us to use our data to investigate possible differences between boys and girls attitudes we assessed the measurement invariance of the final four-factor solution between those two groups.

Initially separate factor analyses were conducted for boys and girls to establish a baseline for comparison. Both models are structurally similar with RMSEA values marginally higher than the recommended cutoff values (Table $\mathrm{B} 1$ ) and so, some residual covariances in each group were allowed to: items $21-19$ in the boy's group and items $14-18$ and 18-3 in the girl's group. The final models presented acceptable fit (Table B1), so we proceed with invariance testing.

Table B1. Goodness-of-fit statistics for the baseline models used to assess measurement invariance.

\begin{tabular}{lcccc}
\hline Model & $X^{2}(\mathrm{df})$ & CFI & TLI & RMSEA (90\% Cl) \\
\hline Boys & $446.88^{* *}(203)$ & .973 & .970 & $.075(.066-.84)$ \\
Boys final & $402.71^{* *}(202)$ & .978 & .975 & $.068(.058-.078)$ \\
Girls & $582.00^{* *}(203)$ & .979 & .976 & $.081(.073-.089)$ \\
Girls final & $479.28^{* *}(201)$ & .985 & .982 & $.070(.062-.078)$
\end{tabular}

Note: $N_{\text {boys }}=214 ; N_{\text {girls }}=284 ;{ }^{* *} p \leq .001$.

Table B2 shows the various fit indices obtained for the invariance tests. As can be seen in this table, Model 1 provided a good fit to the data indicating a similar factor structure across girls and boys (Configural invariance). Constraining factor loadings to equality (Metric invariance), yielded a non-significant $\chi^{2}$ test of model comparison supporting the invariance assertion (Model 2) and so we proceeded to test for Scalar Invariance (Model 3). Model 3 had good fit indices, but the $\chi^{2}$ test for model comparison was significant demonstrating that one or more thresholds were noninvariant. As suggested by Bowen and Masa (2015) we searched for the source of non-invariance by testing the different thresholds. Freeing the third threshold of item 22 (Factor - Anxiety) resulted in non-significant $\chi^{2}$ comparison tests and goodness-of-fit statistics within establish criteria indicating partial scalar invariance (Model 3a). With only one noninvariant parameter found among all tested, we decided for the acceptance of scalar invariance as proposed by several authors (e.g. Dimitrov, 2010; Millsap \& Olivera-Aguilar, 2012). 
Table B2. Fit indices for the invariance tests between boys and girls.

\begin{tabular}{|c|c|c|c|c|c|c|c|c|c|c|}
\hline Model & $x^{2}(\mathrm{df})$ & $\mathrm{CFI}$ & TLI & $\begin{array}{l}\text { RMSEA } \\
(90 \% \mathrm{Cl})\end{array}$ & $\begin{array}{c}\text { Model } \\
\text { compared }\end{array}$ & $\Delta x^{2}(\mathrm{df})$ & $\Delta \mathrm{CFI}$ & $\Delta \mathrm{TLI}$ & $\triangle \mathrm{RMSEA}$ & Decision \\
\hline $\begin{array}{l}\text { Model 1: Configural } \\
\text { Invariance }\end{array}$ & $880.98^{* *}(403)$ & .982 & .979 & $.069(.063-.075)$ & - & - & - & - & - & Accept \\
\hline $\begin{array}{l}\text { Model 2: Metric } \\
\text { Invariance }\end{array}$ & $890.60 * *(421)$ & .982 & .981 & $.067(.061-.073)$ & M1 & $24.01(18)$ & 00 & .02 & -.02 & Accept \\
\hline $\begin{array}{l}\text { Model 3: Scalar } \\
\text { Invariance }\end{array}$ & $919.62 *(461)$ & .983 & .983 & $.063(.057-.069)$ & M2 & $82.1^{*}(58)$ & .01 & .02 & -.06 & Reject \\
\hline $\begin{array}{l}\text { Model3a: Partial } \\
\text { Scalar Invariance }\end{array}$ & $910.56 *(260)$ & .983 & .983 & $.063(.057-.069)$ & M2 & 71.37 (57) & .01 & .02 & -.06 & Accept \\
\hline
\end{tabular}

Notes: $N=498 ; N_{\text {boys }}=214 ; N_{\text {girls }}=284 ;{ }^{*} p \leq .005 ;{ }^{* *} p \leq .001$. 